\title{
Simulation of the Temperature Field of the Vehicle Hood Based on ANSYS
}

\author{
Cai Wei $^{1,2, ~ a, ~ Y a o ~ R u i q i a o ~}{ }^{1, ~ b, ~ * ~, ~ H u a n g ~ K u n y a n g 1, ~ c ~}$ \\ ${ }^{1} \mathrm{Xi}$ 'an Hi-tech Institute, Xi'an, Shanxi 710025, China; \\ ${ }^{2}$ Science and Technology on Elctro-Optic Control Laboratory, Luoyang, Henan 471000, China;



Keywords: the hood, temperature field, numerical simulation

Abstract: The study of vehicle temperature field is of great importance for obtaining high-precision infrared images. Based on the ANSYS transient thermal analysis module, the temperature field of vehicle hood is studied in detail. First, the paper draws the vehicle hood model according to the actual size of the vehicle hood. On the basis of the actual heat transfer analysis of the vehicle hood, the temperature field of the hood model is calculated by setting the boundary conditions on the basis of the actual test environment of the vehicle. Compared with the actual test and the simulation results of the model, the results show that the simulation results of the temperature field model built in this paper have high accuracy and good practical value.

\section{Introduction}

At present, most of the researches on vehicle temperature field are concentrated on the passenger compartment of vehicles. This is because the thermal comfort of the crew cabin has a direct connection with the consumer experience, making the automakers and researchers put a lot of energy on the temperature field of the crew cabin ${ }^{[1-8]}$. However, the temperature field of the hood is not studied in detail. In most cases, the whole surface temperature of the hood of the vehicle is often treated as a fixed temperature value when the whole temperature field of the vehicle is built ${ }^{[9-10]}$, which is obviously not in accordance with the actual temperature distribution on the surface of the hood. Although some documents did not take the hood temperature as a fixed value, they did not take into account the heat diffusion in the heat transfer process of the hood ${ }^{[11-13]}$.All these factors make the result of vehicle engine hood temperature field model not accurate enough.

In order to analyze the temperature distribution of the hood accurately, a temperature field model of the hood is established based on the heat balance equation. Comparing the model simulation and experimental results, the two have good consistency in the temperature distribution and temperature values of the hood. This fully shows that the rationality and accuracy of the modeling method in this paper are in line with the actual situation. 


\section{The Temperature Field Model of the Hood}

\subsection{Mathematical model of heat transfer}

The analysis of the ar structure shows that the effect of the engine on the surface temperature of the target is achieved through the two ways of heat radiation from the target top and the heat conduction of the target chassis ${ }^{[11]}$. The hood has no direct contact with the internal parts of the front part of the car. Therefore, the heat source inside the front of the vehicle is mainly through heat radiation to transmit heat to the hood. To further determine the heat source components inside the front end of the car received by the hood. Infrared thermal imager is used to photograph the internal components of the front of a civil car that has been running for a period of time. The infrared gray scale of the temperature distribution inside the vehicle is shown in figure 2.

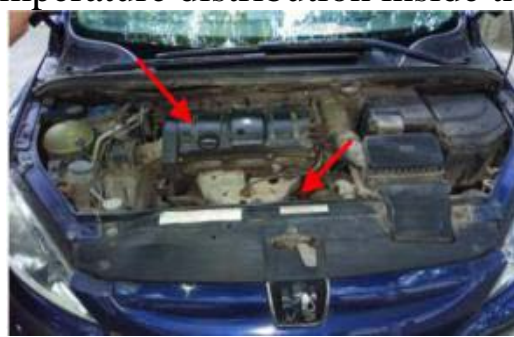

Fig. 1 Internal structure diagram of the car

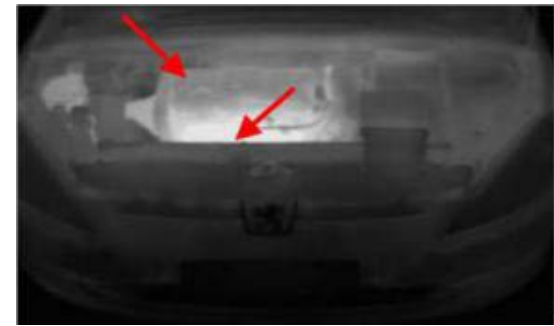

Fig. 2 Interior infrared gray scale of the car

Comparing the shape and geometric position of the internal parts of vehicle in fig. 1 and fig.2, it can find that the main source of heat source inside the vehicle has two components. One is the surface of the engine and the other is the white part next to the engine. At the same time, the air gap in the front intake grille and the chassis structure makes the outside air flow into the interior of the car, resulting in convection heat transfer with the surface of the engine cover. On this basis, the heat transfer process of automobile engine cover is analyzed by the node network method. Fig. 3 is a schematic diagram of heat exchange corresponding to discrete nodes on the upper and lower surfaces of the hood.
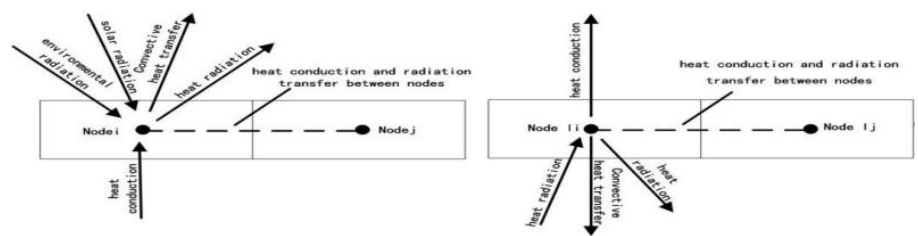

Fig. 3 Heat exchange diagram of the surface node upper and under the hood

The heat balance method is used to establish the heat balance equation (1) and (2) for the surface node on the engine cover and the corresponding lower surface node by heat balance method. On the left side of the equation is transient term, which indicates the change of internal energy of node per unit time. The right side of the equation is the energy transmitted by the node in the unit time due to conduction, convection and radiative heat transfer.

$$
\begin{aligned}
& m_{i} c_{i} \frac{d T_{i}}{d t}=Q_{c v i}+Q_{c d i}+Q_{\text {radi }} \\
& m_{l i} c_{l i} \frac{d T_{l i}}{d t}=Q_{c v l i}+Q_{c d l i}+Q_{\text {radli }}
\end{aligned}
$$

Where $m$ is node quality, $c$ material specific heat capacity, $T$ is node temperature, $t$ is time, $Q_{c v}$ is the thermal convection energy of the imported node, $Q_{c d}$ is the heat conduction energy of the imported 
node, $Q_{\text {rad }}$ is the energy of the heat radiation of the node.

For automobile hood, the heat balance equation is established by means of (1) and (2) simultaneous upper and lower surface nodes. Under the condition of definite solution, the thermal equilibrium equation of the upper and lower surface nodes of the simultaneous engine hood is solved, and the temperature values on each node can be obtained.Then the temperature distribution and heat transfer condition of the whole vehicle hood can be determined.

\subsection{The physical model of the hood}

Based on the actual vehicle structure and size, the model of the vehicle hood location designed and drawn is shown in figure 4. Using ansys software to divide the model, the total number of engine hood mesh models is 184841, and the total number of nodes is 330340 .

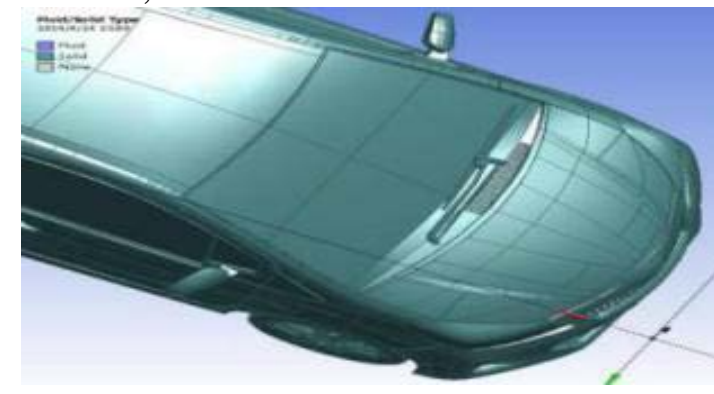

Fig. 4 Image of the hood model

\section{Simulation Calculation of the Hood Model}

\subsection{Parameter setting of the model}

The civil passenger cars used in the test are measured, and the structural parameters of the main components of the hood numerical model are obtained as shown in table 1.

Table 1 The structural parameters of the hood main parts

\begin{tabular}{ccc}
\hline parts & length/(cm) & width/(cm) \\
\hline the hood & 150 & 70 \\
engine & 21 & 43 \\
white part & 13 & 30 \\
\hline
\end{tabular}

The material parameters of the main components of the hood numerical model are shown in table 2.

Table 2 The material parameters of the hood main parts

\begin{tabular}{ccccc}
\hline parts & material & $\begin{array}{c}\text { density } \\
\rho /\left(\mathrm{kg} \cdot \mathrm{m}^{-3}\right)\end{array}$ & $\begin{array}{c}\text { heat } \\
\text { conductivity } \\
\lambda /\left(\mathrm{W} \cdot \mathrm{m}^{-1} \mathrm{~K}^{-1}\right)\end{array}$ & $\begin{array}{c}\text { Specific heat } \\
\text { capacity } \\
\mathrm{c} /\left(\mathrm{J} \cdot \mathrm{kg}^{-1} \mathrm{k}^{-1}\right)\end{array}$ \\
\hline $\begin{array}{c}\text { engine } \\
\text { cover } \\
\text { the hood }\end{array}$ & $\begin{array}{c}\text { polyamide } \\
\text { aluminium } \\
\text { structural } \\
\text { steel }\end{array}$ & $\begin{array}{c}1050.00 \\
2770.00\end{array}$ & 0.24 & 1400.00 \\
& 7850.00 & 60.5 & 875.00 \\
\hline
\end{tabular}

The surface characteristic parameters of the main components of the hood numerical model are shown in table 3. 
Table 3 The optical characteristic parameters of the hood main parts surface

\begin{tabular}{cccc}
\hline parts & absorptivity & reflectivity & emissivity \\
\hline engine cover & 0.7 & 0.3 & 0.95 \\
interal surface of the hood & 0.83 & 0.17 & 0.92 \\
exteral surface of the hood & 0.8 & 0.2 & 0.95 \\
white part & 0.7 & 0.3 & 0.90 \\
\hline
\end{tabular}

\subsection{Boundary condition setting}

Based on the environmental condition of vehicle test shown in figure 5, the boundary conditions of the numerical model are set. The temperature measuring module layout inside and outside the automobile engine cover is shown in figures 6,7 and 8 . The temperature data of the corresponding nodes can be collected through the temperature measuring module.

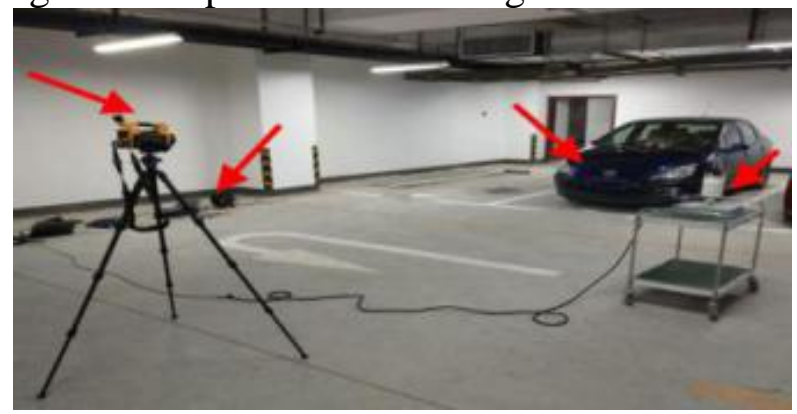

Fig. 5 The car test equipment layout



Fig. 6 The surface temperature measurement module on the hood

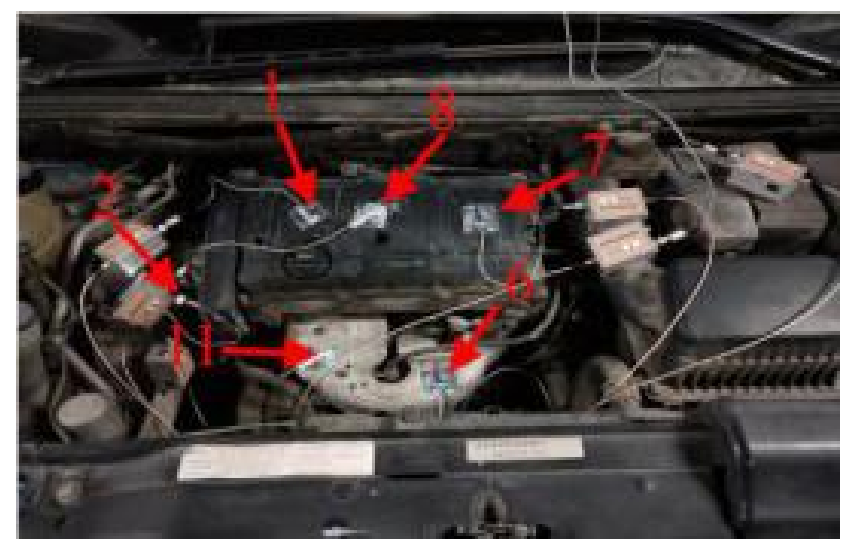

Fig. 7 The surface temperature measurement 


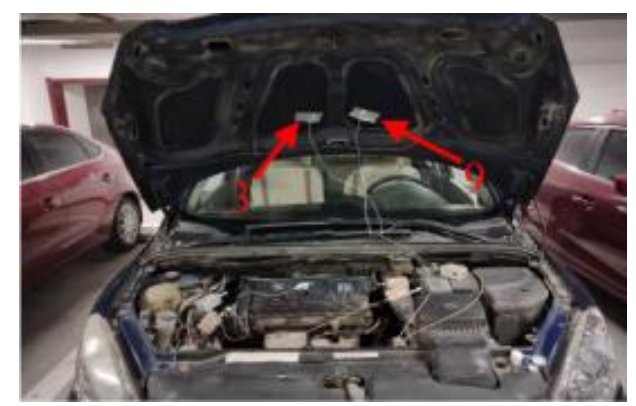

Fig. 8 The surface temperature module on the engine measurement module under the hood

\section{Calculation Results and Analysis}

From figure 8, it is found that irregular air interlayers are distributed inside the hood of the vehicle engine. The existence of these interlayers will greatly affect the temperature distribution of the hood. For this reason, there are 3 layers of air interlayer in the modeling process, and the relevant parameters of the engine hood model are shown in table 4.

Table 4 The related parameters of the layered parts of the hood model

\begin{tabular}{lccccc}
\hline The hood & $\begin{array}{c}\text { thicknes } \\
\mathrm{s} /(\mathrm{mm})\end{array}$ & material & $\begin{array}{c}\text { density } \\
\rho /\left(\mathrm{kg} \cdot \mathrm{m}^{-3}\right)\end{array}$ & $\begin{array}{c}\text { heat } \\
\text { conductivity } \\
\lambda /\left(\mathrm{W} \cdot \mathrm{m}^{-1} \mathrm{~K}^{-1}\right)\end{array}$ & $\begin{array}{c}\text { Specific heat } \\
\text { capacity } \\
\mathrm{c} /\left(\mathrm{J} \cdot \mathrm{kg}^{-1} \mathrm{k}^{-1}\right)\end{array}$ \\
\hline Upper surface layer & 5 & aluminium & 2770.00 & 226 & 875.00 \\
Middle layer & 3 & air & 1293 & 0.03 & 103.00 \\
Lower surface layer & 2 & aluminium & 2770.00 & 226 & 875.00 \\
\hline
\end{tabular}

Considering the end of the experiment from 21:00 to 22:40, the computation time of the model is set to 6000 seconds. The simulation results of the hood model are compared with the experimental results.

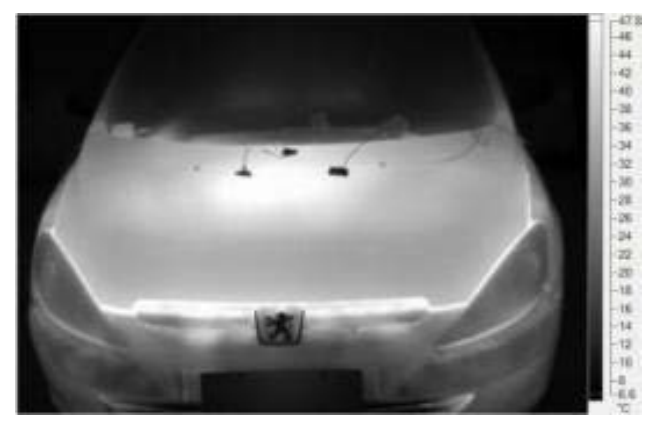

Fig. 9 Gray-scale map of the hood

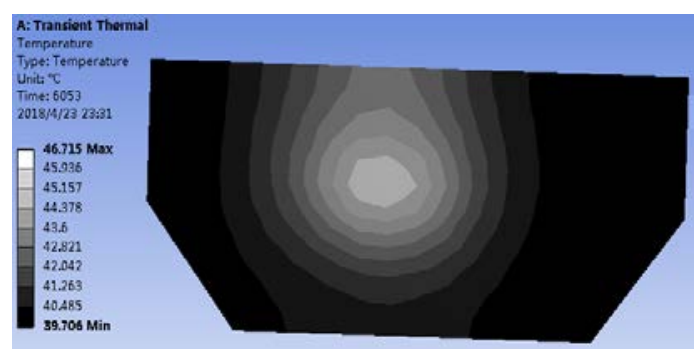

Fig. 10 The hood model temperature distribution 
It can be seen from figure 9 that the temperature distribution on the outside surface of the hood is basically within the range of 39 degree -47.8 degrees. The temperature distribution of the outer surface of the engine cover model in figure 10 is basically within the range of the temperature range of 39 degrees -46.2 degrees, which basically coincides with the temperature range of the test.

In order to analyze the numerical results of the temperature distribution of the two more accurately. With the post-processing function of ANSYS software, the temperature data of the temperature sensor node 5 and node 10 outside the engine cover in figure 8 corresponding to the engine hood model are collected. The collected temperature data and the measured temperature data are drawn into curves for comparison. The plotting results of various temperature curves of temperature sensor module node 5 and node 10 are shown in figures 11 and 12 .

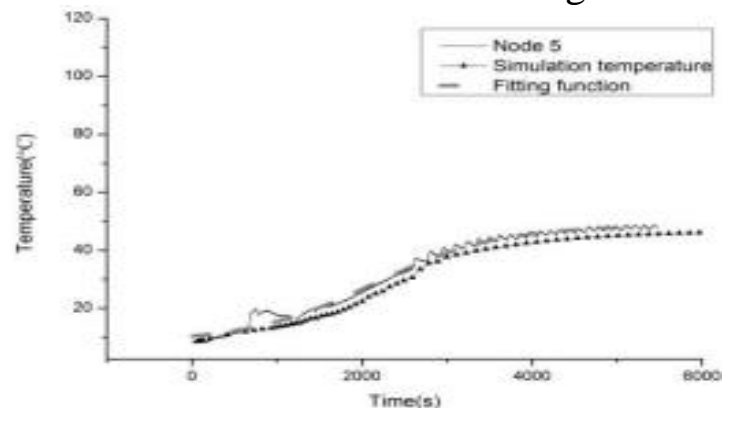

Fig. 11 The improved model node 5



Fig.12 The improved model node temperature data curve 10 temperature data curve

The temperature curves calculated by the models of nodes 5 and node 10 in figure 11 and figure 12 are compared with the temperature curves collected by the actual modules. The change trends of the two are in good agreement with the numerical results. This further proves the accuracy of the calculation results from the numerical point of view.

\section{Conclusion}

In this paper, the temperature field model of vehicle engine cover is established based on the civil car. In the process of modeling, not only the influence of ambient air temperature and wind speed, but also the influence of the material, structure and thermal conductivity of the hood components on the accuracy of the simulation results is considered. The comparison between the simulation and experimental results shows that the results of the modeling method in this paper are true and conform to the actual situation and have good practical application value.

\section{References}

[1] Zhang Wencan, Chen Jiqing, Lan Fengchong. Research on windshield glazing property effect on vehicle cabin temperature under solar radiation[J]. Journal of Mechanical Engineering, 2011,47(22): 119-125.

[2] Zhang Wenge. Optimal design of vehicle air condtion based on thermal comfort of human body [D]. Changsa: 
College of Mechanical and Vehicle Engineering, Hunan University, 2012.

[3] Cui Jinnan. Transient CFD analysis on airconditioner cooling of automobile occupant caqbin[J]. Computer Aided Engineering, 2012,21(6):54-57.

[4] Li Lifen. Simulation and experimental of vehicle cabin and components thermal load under natural exposure [D]. Guangzhou: South China University of Technology, 2015.

[5] Shen Hongli.Analysis and optimization on passenger compartment thermal comfort [D]. Hunan: Hunan University, 2013.

[6] Yang Shujuan. Analysis of the thermal comfort in vehicle's cabin [D]. Chongqing: Chongqing University, 2016.

[7] Huang Musheng. Thermal comfort analysis of microbus passenger compartment based on CFD [D]. Hunan: Hunan University, 2013.

[8] Lan Fengchong, Wei Wen, Guo Qiaoyan, et al. Numerical simulation and experimental study of automotive passenger compartment tempeerature field [J]. Journal of Hunan University ,2015, 42(10): 23-30.

[9] Peng Mingsong. Digital simulation of complicated ground environment and typical targets optical properties [D]. Beijing: Beijing Institute of Technology, 2016.

[10] Mu Chengpo, Peng Mingsong, Gao Xiang, et al. Infrared image simulation of ground maneuver target and scence [J]. Journal of Beijing Institute of Technology, 2016,25(2): 247-253.

[11] Yu Yanwen, Liu Yijun. Computer modeling and simulation for infrared image of ground objects [J]. Infrared and Laser Engineering, 2008,37(S2): 417-420.

[12] Yu Yanwen, Liu Yijun. Computer simulation of vehicle infrared images [J]. Computer Simulation, 2006, 23(12):209-211.

[13] Weijie Yu, Qunsheng Peng, Hongming Tu, et al. An infrared image synthesis model based on infrared physics and heat transfer [J]. International Journal of Infrared and Millimeter Waves, 1998,19(12): 1661-1669. 